\title{
Error Analysis of Students' Essays: A Case of First Year Students of the University of Health and Allied Sciences
}

\author{
Benjamin Amoakohene ${ }^{1}$ \\ ${ }^{1}$ Department of General and Liberal Studies, University of Health and Allied Sciences, Ghana \\ Correspondence: Benjamin Amoakohene, Department of General and Liberal Studies, School of Basic and \\ Biomedical Sciences, University of Health and Allied Sciences, PMB 31, Ho, Volta Region, Ghana. E-mail: \\ bamoakohene@uhas.edu.gh
}

Received: May 30, 2017

Accepted: June 28, 2017

Online Published: July 23, 2017

doi:10.5430/ijhe.v6n4p54

URL: https://doi.org/10.5430/ijhe.v6n4p54

\begin{abstract}
Writing is considered as a daunting task in second language learning. It is argued by most scholars that this challenge is not only limited to second language speakers of English but even to those who speak English as their first language. Thus, the ability to communicate effectively in English by both native and non-native speakers requires intensive and specialized instruction. Due to the integral role that writing plays in students' academic life, academic literacy has garnered considerable attention in several English-medium universities in which Ghanaian universities are no exception. It is therefore surprising that prominence is not given to Academic Writing and Communicative Skills at the University of Health and Allied Sciences (UHAS). In this paper, I argue for much time and space to be given to Academic Writing and Communicative Skills, a programme that seeks to train students to acquire the needed skills and competence in English for their academic and professional development. This argument is based on the findings that came out after I explored the errors in a corpus of 50 essays written by first year students of UHAS. The findings revealed that after going through the Communicative Skills programme for two semesters, students still have serious challenges of writing error-free texts. Out of the 50 scripts that were analyzed, 1,050 errors were detected. The study further revealed that $584(55.6 \%)$ of these errors were related to grammatical errors, $442(42.1 \%)$ were mechanical errors and $24(2.3 \%)$ of the errors detected were linked to the poor structuring of sentences. Based on these findings, recommendations and implications which are significant to educators, policy makers and curriculum developers are provided. This study has implications for pedagogy and further research in error analysis.
\end{abstract}

Keywords: Error Analysis, Mistakes, Academic Writing, Communicative Skills

\section{Introduction}

Communication is considered as one of the most distinct features of every speech community. That is, people use language to communicate their thoughts and express their opinions to one another either through writing, speaking or other non-verbal forms of communication. Though not every form of communication is linguistic, it is obvious that the act of using language to communicate is the most frequently used mode of communication in every speech community (Gumperz, 2009). It is an undeniable fact that writing is one of the most dominant forms of communication that uses language. This mode of communication is highly considered to be a daunting task both in the first and second languages (Hourani, 2008; Richards \& Renandya, 2002). That is, writing is considered to be the most difficult aspect of the language abilities and skills that students need to acquire (Corder, 1974). This difficulty as stressed by Richards \& Renandya (2002) is not only limited to generating and organizing ideas but also relates to the inability of students to translate these notions and ideas to "legible text" (p.1). As a productive skill, writing is considered as a very difficult task especially with non-native speakers of English (Al Buainain, n.d.).

Though writing has been considered as a very difficult exercise, students cannot do away with it. This is because, writing serves as an indispensable feature in the academic lives of students and as such, the link between academic literacy and tertiary education cannot be overemphasized by scholars (Afful, 2007).The problem of writing becomes very much compounded when students are made to express themselves in a second language - English Language. The reason is based on the fact that most students lack the skills to communicate effectively in English. Considered to be a global language, English language has been adopted as an official language and as a medium of instruction in Ghana, a multi-lingual society. The antecedent to the adoption of English as an official language can be traced to the coming of the European traders and missionaries to Ghana as well as the dominance of the English Language across 
the globe. That is, today, the massive spread of English worldwide and the roles that it plays as the medium of instruction in most universities as well as its role as the language of intra and international trade, global politics and communication have left Ghana with no option than to adopt English as its official language so as to be "counted as a significant stakeholder in the global village as the language has come to stay and become a modern Ghanaian artifact" (Adjei, 2015:62). Therefore, for students within the various academic levels, especially within the tertiary level, to communicate effectively in discourses within their respective disciplines, they need to gain competence in the rules governing the usage of the English Language. However, it has always been the case that performance in English Language in Ghana, especially within the university setting, "has been described in various unpalatable terms to reflect concerns about its falling standard" (Mireku-Gyimah, 2014:24). Thus, most students at the tertiary levels are not able to demonstrate high level of flair and sophistication in most of their academic essays. This suggests that their proficiency in English is highly not up to the required standard (Amua-Sekyi, 2000). The falling standard of English at the various levels of the academic ladder has been traced to a lot of factors. Gyasi (1990) relates these falling standards to lack of qualified teachers, text-books and the absence of reading culture. From the perspective of Darko et al. (2008), these falling standards are linked to the predominant use of Pidgin English by students whilst Mireku-Gyimah (2014) associates this problem to poor teaching and learning of English Language at the Junior and Senior High School levels. This therefore reflects in the poor standard of English at the university level. Other scholars also argue that most students (non-native speakers of English) face these challenges because of the influence of their respective L1 languages (Cedar, 2004 \& Lado, 1957).

In order to help students communicate effectively in the academic discourse community at the tertiary level, English for Academic Purposes (EAP) programme known in the Ghanaian context as Communicative Skills (CS) (Afful, 2007), has been mounted in institutions of higher learning especially in the various universities in Ghana. This course is normally taught to first year students with the aim to prepare and equip them with the needed skills that they require to effectively go through the daunting writing task ahead of them. This situation exists at the University of Health and Allied Sciences (UHAS) where students go through the Communicative Skills programme which is known on UHAS campus as Academic and Communicative Skills, for two semesters (two hours for the first semester and three hours for the second semester). However, it has been observed that after students have gone through this course for the first two semesters, they still have challenges in writing error-free texts. This confirms the general concerns raised by previous studies about the falling standard of English at the tertiary level. That is, this observation is in line with studies conducted by Odamatten et al. (1994), Dako (1997) and Anyidoho (2002) at the university of Ghana; Gbeze (1997) and Awuah-Boateng (1998) at the University of Cape Coast; Mahama (2012) at the University of Development Studies; Mireku-Gyimah (2014) at the University of Mines and Technology; Dako et al. (1997) and Gogovi (1997) at the University of Education, Winneba.

Despite the peculiar role that academic writing plays in "socializing students into discourse of subjects and disciplines in universities (Pineteh, 2013: 2), it has been given less attention and space at UHAS. Thus, although students are struggling to maintain academic writing standards at UHAS, I am yet to find any rigid and comprehensive strategies to enhance the academic writing skills of UHAS students. The most surprising thing is that there have been numerous attempts to even reduce the number of credit hours from five to three and from two semester course work to one semester whilst some even think it should be considered as a zero credit hour course, a step which will make the future so bleak for our students in the sense that it is going to have a very bad implication on graduates that will be produced in subsequent years. This, to a very large extent, threatens the image of UHAS as an academic institution. I therefore argue in this paper for the need for curriculum developers to give much space and time to Academic and Communicative Skills which has arguably been tagged as an "auxiliary" course at UHAS. To buttress the need for much space and time for the Academic and Communicative Skills programme at UHAS, I explored the language use in students' writing by looking at the type of errors in the essays of first year students of UHAS after they have been taught Academic and Communicative Skills for two semesters (five credit hours). The result of this study revealed the poor state of students writing even after they have gone through the Academic and Communicative Skills programme for two intensive semesters, hence reveals the danger that lies ahead if the credit hours for this programme is subsequently reduced or made a zero credit hour course.

The study is significant in three main ways. First, it has pedagogical implication by providing an insight to Communicative Skills lecturers about challenges that students face in their writing so as to help these lecturers make informed decisions about their instructional materials and teaching methodology. Aside this, the numerous errors that were identified in the scripts of students provide a strong justification for the argument raised in this paper for much time and space to be given to Academic and Communicative Skills at UHAS and as such, the subject must not be 
treated as an "auxiliary" course nor a zero credit hour course. Coupled with these, the study adds to the existing literature on error analysis.

\section{Aims of the Study}

The aim of this study is to explore the competence level of first year students of the University of Health and Allied Sciences after they have gone through the Academic and Communicative Skills programme for two semesters. That is, the paper seeks to analyze whether the students are able to apply the knowledge they gain in the Academic and Communicative Skills classes by writing error-free texts or whether they still face challenges in avoiding errors in their essays and if so, to identify the type of errors that typify their writing. To a very large extent, the study seeks to extend the scope of existing literature by doing an error analysis of first year UHAS students in order to find out the type of errors that they commit in their essays.

\section{Review of Pioneering Studies on Error Analysis}

Error analysis has attracted the attention of most scholars over the last two decades. This stems from the fact that it is considered as an analytical tool that learners use in order to learn (Khansir, 2013). The outcome of error based analysis of students' essays therefore serves as an effective means of improving the language of students as it gives them an insight into some errors that they usually make in their writing. Errors can be conceptualized as "a noticeable deviation from the adult grammar of a native speaker reflecting the inter-language competence of the learner" (Brown, 1994:205). Inter-language errors can be defined as a type of speech or writing errors that normally occur when a learner is starting to gain proficiency in the new, or "target" language but has not mastered it. That is, it is a distorted form of the target language that predominantly contains errors caused by the inappropriate use of aspects of the learner's native language while trying to speak the target language. This means that "errors are systematic deviation where learners have not learnt something they consistently get wrong" (James 1998:77). As established in the literature, "errors" are not the same as "mistakes". Errors are considered to be gaps in learners knowledge which normally occur because learners are not conscious of them whilst mistakes are related to irregular inconsistencies in performance in the usage of a particular language (Ellis, 1994). Tarigan (1995) believes that these inconsistencies are mostly linked to factor of performances. However, Norrish (1983) is of the view that three main issues make students commit errors in their writing and these include carelessness on the side of the students, first language interference (the influence of the native language of the learner on his or her acquisition of the target language) and translation.

Dominant among research works in error analysis within the ESL (English as a Second Language) context is the scholarly work of Quibol-Catabay (2016) who explored the frequency and the types of sentence errors that characterize the writings of 30 second year students from the College of Business, Entrepreneurship and Accountancy of State University, Andrews Campus. The data for the study was specifically made up of sentences written by the respondents after they have listened and watched an audio-visual prompt that was titled as "Rabbit and Turtle Story". The mixed method approach was used as the research design. The study revealed three main categories of errors - mechanical errors, grammatical errors and structural errors. Qui-Catabay (2016) further stressed that punctuation mark errors dominated errors that were linked to the mechanical category whereas wrong use of tense was prototypical of errors in the realms of the grammatical category. Fragments, as stressed by Qui-Catabay (2016), dominated errors within the structural level (structural category). Aside these findings, the analysis further proved that the structural category of errors, with a frequency of 63, was the highest type of errors made by the respondents. This was followed by the grammatical category with 43 errors and the mechanical category with 31 errors.

On the other hand, Pineteh (2013) from the South African perspective, shed light on the kind of difficulty that undergraduate students face in applying the rules of usage of the English Language to communicate in writing. Specifically, the study had as its focus to explore challenges that students of Cape Peninsula University of Technology, South Africa, face in their writing. The researcher had as his prime objective to explore this concept from six main perspectives which included aspects such as lack of mastery of academic writing conventions, analysis of writing topics, using writing to construct social identities, ability to research and apply knowledge across different contexts and poor sentence skills. Aside these, Pineteh (2013) also explored the implications associated with these challenges for students' academic development and possible practices that can help eradicate these challenges in students writing. The qualitative research design was used to collect empirical data. The data was collected by interviewing twenty second year students and four lecturers. The analysis revealed that the reasons for the academic writing challenges of students in the University of Technology are as a result of students' linguistic and general literacy backgrounds, their attitudes towards academic writing and the privileging of middle-class literacy practices 
in South African higher education. Pineteh (2013) further suggested that to curb this situation, there should be the need for the integration of academic literacy in disciplinary curricula, the promotion of multimodalities of teaching and assessment as well as collaboration between language lecturers and core course specialists. Pineteh (2013) further stressed the need for the students to engage in intensive academic reading and writing workshops, as well as increased formative feedback by the respective lecturers who handle the academic writing courses at the University.

Closely related to the above studies, Sarfraz (2011) also applied the error analysis principle from the perspective of Ellis's (1994) procedural analysis of errors (collection of sample of learner language, identification of errors, description of errors, explanation of errors, and evaluation of errors) in analyzing 50 essays written in English by Pakistani undergraduate students. The study purposely had as its aim to provide an insight into language learning problems which occur when L2 learners in the context of Pakistani undergraduate students try to internalize the rules of the target language (English Language). The findings of the study as stressed by Sarfraz (2011) revealed two main types of errors - inter-language errors and mother tongue interference errors (see page 3). Sarfraz (2011) further argued that the percentage of the occurrences of inter-language errors superseded that of errors resulting from the interference of mother tongue.

Still within the ESL setting, specifically within the Ghanaian context, Amuzu and Asinyor (2016) explored the causes of consistent errors that characterize the writings of students within the Ghanaian context. As a speech community that accepts pidgin as a variety of English, Ghana is seen as a place where Pidgin is spoken, especially in the Senior High Schools and tertiary institutions. These researchers in their paper sought to justify the fact that the challenges that most Ghanaian students face in applying the rules of usage of the English Language is as a result of the consistent use of pidgin by these students. The data for the study comprised two groups of students - students that were identified as speakers of School Pidgin English and those identified as non-speakers of School Pidgin English. These two groups of students were made to go through a writing process by writing an essay on a given topic. The researchers further analyzed the grammatical and spelling errors that typified the essays of the students that were analyzed. As posited by Amuzu \& Asinyor (2016), none of the errors committed by these students was solely linked to the School Pidgin English (SPE) speakers but those who were identified as non-speakers of School Pidgin English also made errors in their essays. This finding revealed that speaking SPE is not the sole source of errors in students' essays. However, the researchers posited that most of the errors committed by the students were highly linked to the students' mother tongues and to certain writing systems they use on electronic media platforms.

In related developments, Adjei (2015) also analyzed subordination errors in students writing within the context of selected Colleges of Education in Ghana. The study had as its main focus to explore how students of the selected Colleges of Education handle one important aspect of subordination in their writing. The data for this study comprised written scripts and texts written by 150 students of the selected Colleges of Education. The analysis of the data as highlighted by Adjei (2015) revealed that students of the selected Colleges of Education have challenges in the use of subordination as well as identifying the types and functions of subordinate clauses in sentences. Thus, students were not able to appropriately make use of subordinators to link their ideas together in their essays. Adjei (2015) further recommended the need for much time and space to be given to the teaching of subordination at the Colleges of Education and other levels of education in Ghana so as to enable students achieve coherence in their essays.

Moreover, Mireku-Gyimah (2014) also explored the kind of errors that featured in the English Language usage of final year students of the University of Mines and Technology. The study made use of data from anonymous comments of students on their lecturers' teaching performance as far as the Communicative Skills programme is concerned. In order to get the right information from the respondents, the researcher made the respondents write comments about their lecturers performance at their (respondents) leisure time. The analysis revealed that with a total number of 716 comments written by the students, 216 of these sentences were faulty and these faulty sentences constituted nine different error categories. As stressed by Mireku-Gyimah (2014), dominant among these errors that were identified in the data included wrong register (wrong tone of language and vocabulary) misuse and the least identified was wrong concord (subject-verb disagreement). The implication of this study as argued by the researcher prompts the Academic Writing and Communicative Skills Centre at the University of Mines and Technology about the existence of challenges that final year students face in expressing themselves correctly in English. The researcher further recommended the need for students to pay more attention to their English and writing skills as they enter the world of work as well as the need for the Communicative Skills programme to be expanded and extended beyond the first year in order to make students gain adequate competence in English for their academic and professional development. 
Within the EFL (English as a Foreign Language) context, Listiani (2014) explored errors in students' English writing at SMK Bakti Purwokerto. Specifically, the research had as its main focus to explore the writing abilities of students in second grade of SMK Bakti Purwokerto by investigating the types and level of grammatical and lexical errors made by these non-native speakers of English as well as the percentage of each type of error that was noticed. By making use of descriptive research design as well as the random sampling technique, Listiani (2014) explored the English writing of 72 students. The result confirmed that none of the students demonstrated qualities of a very good performance with respect to the application of the rules of usage of the English language in their respective essays. However $43.05 \%$ of the students were noted to be within the category of good, 25\% (enough category), 30.55\% (bad category) and $1.38 \%$ (fail category). Aside this, the findings revealed that the grammatical errors that were identified in the data included errors in tense (25.44\%), omission of "to be" (18.89\%), addition of "to be" $(13.35 \%)$, errors in composing interrogative sentences $(8.81 \%)$, errors in using articles $(7.05 \%)$, errors in using prepositions $(6.80 \%)$, omission of subject (6.04\%), errors in possessive case (4.78\%), misordering in composing adjective phrase (3.02\%), errors in using pronouns $(2.26 \%)$, omission of main verbs $(1,15 \%)$, the substitution of auxiliary $(1.26 \%)$ and errors in using adverbs $(0.75 \%)$. In addition, the analysis confirmed that challenges with inappropriate use of words in specific contexts, spelling, part of speech, wrong diction, Indonesian words usage, wrong tense and inappropriate use of the plural forms of words featured in errors that were committed at the lexical level.

Also, Hamdi (2005) analyzed written grammatical errors of Tunisian learners of English in the EFL context. The study made use of 18 third year Tunisian students in the area of Business English at the ISEAH Institute of Kef in Tunisia. By making use of 18 written essays by the 18 respondents who were all non-native speakers, Hamdi (2005) explained the kind of errors that dominated the writing of the selected students. The findings of the study revealed that the error types that dominated students writing were wrong usage of tenses, morphology, prepositions, articles, verbs, and relative pronouns. That is, these areas were "trouble spots" that impeded easy comprehension of essays written by the respondents.

In contrast with the aforementioned studies which solely focused on errors in the writings of learners either from the ESL or EFL context, Khansir (2013) did a comparative study of written errors in English Language by EFL and ESL learners at undergraduate levels. The study also had as an additional aim of providing remedy to curb the situation by outlining and recommending measures that can be adopted to curb those errors that were identified in the students' written texts. By making use of 200 non-native speakers of English students from two main geographical settings (Indian \& Iran) at the undergraduate levels, Khansir (2013) posited that the Iranian students committed 3,045 errors in their writing while their Indian counterparts had 3,274 errors. Khansir (2013) further confirmed that "punctuation" errors dominated the errors that were identified in the essays of students from the two different cultures. That is, there were 1,387 instances where punctuation marks were wrongly used by students from the two cultures. The number of errors made by the Indian students in the use of punctuation marks was 718 while the Iranian students committed 669 punctuation errors. The researcher further argued that wrong spelling was noted to be the least error type that was identified in the essays of students from the two cultures. The Iranian students were noted to have wrongly spelled words on 578 instances whilst the Indians on 472 instances misspelled words.

The literature review shows the extent to which scholars have explored errors in students writing especially within the context of Ghanaian Universities - Amuzu \&Asinyor (2016), Adjei (2015), Mireku-Gyimah (2014), Mahama (2012), Anyidoho (2002), Awuah-Boateng (1998), Dako (1997), Gogovi(1997) and Odamatten et al.(1994). A detailed analysis of the literature on error analysis shows that there is no significant difference between the errors detected in both the ESL and EFL contexts. This highlights the complex nature of the writing process in English language especially by non-native speakers of English. However, with all these numerous studies especially at various Ghanaian Universities, I am yet to find a study that has explored errors within students' writing in the context of the University of Health and Allied Sciences, one of the public universities in Ghana. It is based on this gap that this study seeks to explore the type of errors that typify the essays of first year students of the University of Health and Allied Sciences.

\section{Methodology}

\subsection{Research Design}

The research made use of the qualitative research design because the analysis was purely descriptive in nature. Though there were some few instances whereby the study made use of some frequency counts to rate errors identified in the students essays, it is an undeniable fact that the research was skewed towards the descriptive approach. The study adopted the qualitative research design because the qualitative research design typically makes use of in-depth and verbal description in place of numerical data. That is, the qualitative research design prioritizes 
an in-depth analysis, description and interpretation of verbal behavior as against predominant use of numerical data (Afful \&Tekpetey, 2011).

\subsection{Instrument}

The study had the University of Health and Allied Sciences as its target population. Specifically, the study limited its scope to first year University of Health and Allied Sciences Students who have gone through the Academic and Communicative Skills Programme for two semesters. As an Assistant Lecturer who teaches Academic and Communicative Skills at the University of Health and Allied Sciences, I selected the participants for this study from the 200 Academic and Communicative Skills (UHAS 116) scripts that I marked at the end of the 2016/2017 Second Semester Examination. That is, the study made use of the probability sampling procedure specifically, the random sampling method, to select 50 scripts out of the 200 scripts that I marked. The random sampling was used in order to give all the variables (scripts) equal chance of been selected for the study. The research made use of 50 scripts based on the justification that most pioneering research works in error analysis made use of 30 data - Amuzu \& Asinyor (2016), Quibol-Catabay (2016), Mireku-Gyimah (2014) and Ulla (2014). There were cases whereby some of the studies made use of less than 30 respondents - Hamdi (2005), 18 respondents, Pineteh (2014), 24 respondents and Amelia (2013), 15 respondents. Those studies that made use of more than 30 respondents include Khansir (2013) who used 200 respondents, Listiani (2014), 72 respondents, Al-Buainain (n.d.), 40 respondents and Sarfaraz (2011) who made use of 50 respondents. Per this review, it is justifiable for a study of this nature to make use of 50 respondents because most of the previous studies made use of data that were below 50 .

\subsection{Procedure}

The research made use of the procedural analysis of errors by Ellis (1994). That is, the research explored the errors in the first year students of the University of Health and Allied Sciences by following the steps as used by Ellis (1994). Ellis' (1994) procedural analysis comprises four stages - collection of sample of learner language, identification of errors, description of errors and evaluating the errors identified in the data.

\section{Findings and Discussions}

This chapter seeks to do an analysis and discussions of errors that were identified in the essays of first year students of the University of Health and Allied Sciences in Ho, Volta Region, Ghana. After carefully going through the 50 scripts that formed the data for this study, it was revealed that students were not able to significantly internalize the rules of the usage of the English Language despite the fact that they had gone through the Academic and Communicative Skills programme for two semesters. These errors really impeded easy comprehension of ideas that were advanced by students in their essays. The findings of the study revealed that nine types of errors, which can be grouped into three broad categories typified the students' essays. Table 1 provides a fair description of errors that were realized in the students' essays.

Table 1. Frequency and Rank Distribution of Errors in the Students Essays

\begin{tabular}{llll}
\hline Errors & Frequency & Percentage & Rank \\
\hline Poor Usage of Punctuation Marks & 311 & 29.6 & 1 \\
Concord & 302 & 28.8 & 2 \\
Wrong Tense Usage & 113 & 10.8 & 3 \\
Improper Use of Articles & 97 & 9.2 & 4 \\
Poor Usage of Prepositions & 72 & 6.9 & 5 \\
Poor Spelling & 69 & 6.6 & 6 \\
Poor Capitalization & 62 & 5.9 & 7 \\
Ambiguity & 15 & 1.4 & 8 \\
The Use of Fragments & 09 & 0.8 & 9 \\
Totals & $\mathbf{1 , 0 5 0}$ & $\mathbf{1 0 0}$ & \\
\hline
\end{tabular}

As evident in Table 1, it can be deduced that nine different types of errors were identified in the written texts of first year students of the University of Health and Allied Sciences. These errors include poor usage of punctuation marks, concord errors, wrong tense usage, improper use of articles, poor usage of prepositions, poor spelling, poor capitalization, ambiguity, and sentence fragments. It can be deduced from Table 1 that poor usage of punctuation marks recorded the highest error in the essays of the students. This confirms the finding of Khansir (2013) that improper use of punctuation marks dominated the written texts of non-native speakers of English from two cultural 
settings - Iran and India. The next most dominant error in the students essays was in line with students inability to effectively apply the rules of concord. This was followed by wrong tense usage, improper use of articles, poor spelling and wrong use of capital letters. Errors related to ambiguity was ranked $8^{\text {th }}$ whilst the use of fragments was noted to be the least error that was identified in the data.

A close analysis of the errors highlighted in Table 1 reveals that they can be grouped into three broad categories. That is, errors committed by first year UHAS students can be grouped under mechanical category, grammatical category and structural category of errors. The mechanical category of errors as evident in Table 1, include errors related to poor spelling, poor capitalization, and poor usage of punctuation marks. The grammatical category of errors include errors such as wrong tense usage, poor usage of prepositions, poor usage of the concord rules and the inappropriate use of articles. From Table 1, it can be deduced that the structural forms of errors were only limited to sentence fragments and ambiguity. This finding confirms that of Quibol-Catabay (2016) who also identified these three broad categories of errors (mechanical, grammatical and structural) when he explored errors committed by the Second Year BSENT non-native speakers of English students in the College of Business, Entrepreneurship and Accountancy of the Cagayan State University, Andrews Campus. This shows the commonality that exists between non-native speakers of English in their quest to achieve competence in English irrespective of their geographical setting.

Table 2. Frequency and Rank Distribution of Errors in the Mechanical Category

\begin{tabular}{llll}
\hline Errors & Frequency & Percentage & Rank \\
\hline Poor Usage of Punctuation Marks & 311 & 70.4 & 1 \\
Poor Spelling & 69 & 15.6 & 2 \\
Poor Capitalization & 62 & 14.0 & 3 \\
Total & $\mathbf{4 4 2}$ & $\mathbf{1 0 0}$ &
\end{tabular}

Across the three categories of errors that were identified in the essays of first year UHAS students, the analysis revealed that errors related to mechanical inaccuracies were the second highest error type that characterized the students writing. That is, out of the 1,050 errors identified in the data, $442(42.1 \%)$ were related to errors within the realms of mechanical inaccuracies. As evident in Table 2, these mechanical inaccuracies were related to the poor usage of punctuation marks, poor spelling and inappropriate use of capital letters. Table 2 further makes it clear that the dominant mechanical error as evident in the data set is related to the poor usage of punctuation marks which recorded a frequency of $311(70.4 \%)$ out of the total 442 mechanical errors that were identified in the data. This was followed by poor spelling with a frequency of $69(15.6 \%)$ and inappropriate use of capital letters which also had a frequency of $62(14.0 \%)$.

\subsection{Errors Related to the Poor Usage of Punctuation Marks}

As evident in Table 2, poor usage of punctuation marks was the highest ranked error under mechanical inaccuracy. A detailed analysis of the data revealed that this form of error was linked to the inappropriate use of the comma, period and the apostrophe sign. That is, students lack knowledge in the correct usage of these punctuation marks and this to a very large extent, affects cohesion in their essays. The examples below show instances where students faltered with the use of punctuation marks.

Table 3. Wrong Usage of Punctuation Marks and their Corresponding Correct Forms

Wrong usage of punctuation marks

1. Again you have to cite the source.

2. Therefore to avoid plagiarism one must use three strategies.

3. They have refused to be dressed in the prescribed attire

4. The maxim of relation is when one tries to be informative as possible

5. Its a great pleasure to address this audience on ways of preventing cholera in the Ho municipality.

6. The city of Saboba and it's environs needs a lot of dust bins in order to keep the city clean.

\section{Right usage of punctuation marks}

Again, you have to cite the source.

Therefore, to avoid plagiarism, one must use three strategies.

They have refused to be dressed in the prescribed attire.

The maxim of relation is when one tries to be informative as possible.

It's a great pleasure to address this audience on ways of preventing cholera in the Ho municipality.

The city of Saboba and its environs needs a lot of dust bins in order to keep the city clean. 
The examples in Table 3 show some of the ways in which errors related to mechanical inaccuracy featured in students writing. Examples 1 and 2 are instances of the poor usage of comma in students writing. That is, most of the students demonstrated lack of knowledge in the appropriate use of the comma in their sentence constructions. In example 1 for instance, there should have been a mandatory comma after "Again" and the sentence should have been written as "Again, you have to cite the source". A comma should have also been introduced after the word "therefore" and "plagiarism" in example 2 as in "Therefore, to avoid plagiarism, one must use three strategies". That is, students were not able to identify pauses in their writing in order to use the right punctuation mark in the form of the comma. Examples 3 and 4 also shed light on some of the mechanical inaccuracies in line with improper use of the period. Per the level of the students as first year University students who have read English Language at the Basic and Senior High School levels, as well going through the Communicative Skills programme for two semesters, one would have expected students to demonstrate good command of the usage of the period. However, there were instances in the data where students wrote complete sentences without indicating a full stop. For instance, in examples 3 and 4, there should have been the introduction of periods after those statements were made so as to prompt readers that complete statements have been made. That is, sentences 3 and 4 should have ended with a full stop as in "They have refused to be dressed in the prescribed attire." and "The maxim of relation is when one tries to be informative as possible." respectively. The last two sentences $(5 \& 6)$ on the other hand, project mechanical inaccuracies in line with the inappropriate use of the apostrophe sign. The data revealed that most of the students lack knowledge in the appropriate use of the apostrophe sign and as such, hinders easy comprehension of essays they write. To a very large extent, these students do not know when to use the apostrophe sign and when not to use it. In example 5 of Table 3, the apostrophe sign should have been used in the word "its" as in it's whilst its introduction in sentence 6 in the form of it's should have been avoided. That is, sentences 5 and 6 should have respectively been written as "It's a great pleasure to address this audience on ways of preventing cholera in the Ho municipality."

\subsection{Errors Related to Poor Spelling}

Errors related to poor spelling were noted to be the second highest error type under the mechanical error category. That is, as evident in Table 2, out of the 442 mechanical inaccuracies, $69(15.6 \%)$ of these errors were related to poor spelling. This indicates the limited English Language vocabulary at the disposal of the students and the fact that students do not spend time to read other books that can help them build enough vocabulary as well as express themselves well in English. Some instances of wrong spelling as evident in the students' essays are listed below.

Table 4. Wrong Spellings and their Corresponding Correct Forms

\begin{tabular}{rll}
\hline Wrong forms of words & Right forms of words \\
\hline 7. & $\begin{array}{l}\text { The *informations } * \text { will help you in crediting the } \\
\text { source. }\end{array}$ & $\begin{array}{l}\text { The information will help you in crediting the source. } \\
\text { 8. }\end{array}$ \\
*Normination* of presidential candidates... & $\begin{array}{l}\text { Nomination of presidential candidates... } \\
\text {...put in place to improve on the health of the people } \\
\text { of Ho and also *solicite* for *equipments*. }\end{array}$ & $\begin{array}{l}\text {...put in place to improve on the health of the people of Ho } \\
\text { and also solicit for equipment. }\end{array}$
\end{tabular}

10. It should be very reasonable, it should be *coated*.

11. *Whiles* she was admitted at the hospital...

It should be very reasonable, it should be quoted.

While she was admitted at the hospital...

Examples 7, 8, 9, 10 \& 11 indicate some instances of words that were misspelled by the students. An analysis of the examples above indicates that the word "informations" as indicated in example 7 does not take the $-s$ form and as such should have been written as "information" whilst "normination" in example 8 should have been spelt as "nomination". That is, there is no " $r$ " after the first letter "o" in the word nomination. Also, the word "solicite" in example 9 should have been spelt as "solicit" whilst the "s" in "equipments" should have been dropped and written as "equipment". Also, the word "coated" should have been written as "quoted" and "whiles" is supposed to be written as either "while" or "whilst".

\subsection{Errors Related to Inappropriate Use of Capital Letters}

As indicated in Table 2, this type of error was the least recorded under mechanical inaccuracies. Out of the 442 errors related to mechanical inaccuracies, only 62 instances representing $14.0 \%$ were related to inappropriate use of capital letters. Within the context of this error type, the analysis revealed that most students are unaware of the fact that a capital letter is required when new sentences are written as well as capitalizing the first letters of words that are considered to be proper nouns. Examples of these errors are stated in Table 5. 
Table 5. Errors Related to the Poor Usage of Capital Letters and their Corresponding Correct Forms

\section{Inappropriate use of capital letters Appropriate use of capital letters}

12. Besides, *Building* of Toilet facilities is another project of plan. (sic)

13. I write to remind you of our annual general meeting which was scheduled on the $24^{\text {th }}$ of may, 2017.(sic)

14. I write to invite all nurses and midwives in the Ho municipality for an *annual general meeting*...

15. The *executive board* is pleading with all unit heads...
Besides, building of toilet facilities is another project of plan. (sic)

I write to inform you of our annual general meeting which was scheduled on the $24^{\text {th }}$ of May, 2017.(sic)

I write to invite all nurses and midwives in the Ho municipality for an Annual General Meeting ...

The Executive Board is pleading with all unit heads...

Table 5 provides a fair view of errors related to the inappropriate use of capital letters as indicated in the essays of the students. Most of the students made use of capital letters at instances where they needed not to do so and where they were supposed to use capital letters, they avoided it.

In sentence 12 for example, there was no need for the letters " $b$ " in "building" and " $t$ " in "toilet" to have been capitalized whilst in example 13, the letter " $m$ " in "may" which is a proper noun should have been capitalized as "May". Aside these, the first letters in the expression "annual general meeting" should have been capitalized as "Annual General Meeting" whereas the first letters in "executive board" should have also been capitalized as "Executive Board". These errors related to inappropriate use of capitalization is linked to students inability to differentiate between proper nouns and improper nouns.

Table 6. Frequency and Rank Distribution of Errors under the Structural Category

\begin{tabular}{lccc} 
Errors & Frequency & Percentage & Rank \\
\hline Ambiguity & 15 & 62.5 & 1 \\
Fragments & 09 & 37.5 & 2 \\
Totals & $\mathbf{2 4}$ & $\mathbf{1 0 0}$ &
\end{tabular}

Table 6 provides a general picture of the structural categories of errors that were noticed in students' essay. From Table 6, it could be noticed that two main types of errors were identified under the structural category. These two types of errors include ambiguity and sentence fragments. As demonstrated in Table 1, the structural category of error was the least type of error that featured in the students' essays. That is, out of the total 1,050 errors identified in the data set, only $24(2.3 \%)$ were related to structural category. Within the context of the structural category of errors that were identified, the findings revealed that errors related to ambiguity were ranked as the dominant error type in the students essays. That is, out of the 24 errors under the structural category, 15 (62.5\%) instances were errors related to ambiguity whilst sentence fragments were the least ranked error. Only 9 (37.5\%) out of the total 24 errors under the structural category were associated with sentence fragments.

\subsection{Errors Related to Ambiguity}

Ambiguity is conceptualized in the linguistics literature as a proposition that has more than one meaning. Ambiguity causes distortion in meaning and as such should be avoided in students writing. An analysis of the data proved that only one type of error related to ambiguity was used in the students writing. This ambiguity is linked to dangling modifiers. The examples in Table 7 indicate some instances that students made use of dangling modifiers in their essays. 
Table 7. Errors Related to Ambiguity and their Corresponding Correct Forms

\begin{tabular}{l} 
Ambiguous sentences \\
\hline 1. $\begin{array}{l}\text { To attain freedom in society, } \\
\text { unity must be established } \\
\text { among individuals. }\end{array}$ \\
2. In addressing members at the \\
previous meeting, an \\
announcement was made to \\
remind members about the \\
Fourth Annual General \\
Meeting.
\end{tabular}

3. To prevent cholera in my district, dustbins should be placed at vantage points.

4. Mr. Chairman, Togbe Afedzi $X I V$, the Regional Director of Health Services, in order to control cholera in Ghana, adequate measures should be put in place.

\section{Disambiguated sentences}

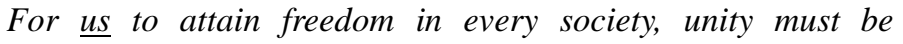
established among individuals.

or

To attain freedom in every society, we must establish unity among individuals"

When the president was addressing members at the previous meeting, an announcement was made to remind members about the Fourth Annual General Meeting.

or

In addressing members at the previous meeting, the president made an announcement to remind members about the Fourth Annual General Meeting.

For us to prevent cholera in my district, dust bins should be placed at vantage points.

or

To prevent cholera in my district, we must place dust bins at vantage points.

Mr. Chairman, Togbe Afedzi XIV, the Regional Director of Health Services, in order for us to control cholera in Ghana, adequate measures should be put in place.

or

Mr. Chairman, Togbe Afedzi XIV, the Regional Director of Health Services, in order to control cholera in Ghana, we must put in place adequate measures in place.

Examples 16, 17, $18 \& 19$ are all instances of how ambiguity in the form of dangling modifiers featured in students' essays. That is, there were instances where students made use of expressions intended to modify words that were not clearly stated. These modifiers therefore attach themselves to wrong head words and as such, bring distortion in meaning. In sentences 16, 17, 18, and 19 above, parts of the sentences in bold indicate instances of dangling modifiers. That is, the words or expressions they seek to modify are not clearly stated in the sentences. In example 16 for instance, the dangling modifier "To attain freedom in every society" does not have any explicit word or phrase that it modifies in the sentences. It therefore behaves as if it is modifying the head word (unity) of the main clause, "unity must be established among individuals". This expression could have been avoided by the introduction of a subject within the dangling modifier. In that respect, the sentence could have been written as "For us to attain freedom in every society, unity must be established among individuals". In this situation, the introduction of the pronoun "us" has made the modifier "to attain freedom in every society" gets its specified modifier in the sentence and as such makes the sentence no more ambigous. Another way this problem could have been dealt with was to maintain the dangling modifier without introducing any overt subject in it but rather replacing the head word of the main clause with another word that relates logically to the dangling modifier. In that context, the sentence could have been written as "To attain freedom in every society, we must establish unity among individuals". In this perspective, the former subject in the main clause -"unity"- has been replaced with a new subject (we) which logically relates to the modifier, "To attain freedom in every society". The same principle was applied to disambiguate sentences 17, 18 and 19 as indicated in Table 7.

\subsection{Errors Related to the Use of Fragments}

As evident in Table 6, this error type - the use of fragments - was the least represented under the structural category of errors identified in the students' essays. That is, 9 (37.5\%) out of the 24 instances of errors under the structural category were linked to the use of fragments in the students' essays where students made use of grammatical constructions that lacked complete thought and meaning and as such, impeded easy comprehension of students 
arguments that they advanced in their essays. Instances of the use of fragments as evident in the data are elaborated in Table 8.

Table 8. Errors Related to the Use of Fragments and their Corresponding Correct Forms

Fragments

5. Secondly, provision of dust bins

6. Last but not the least, good drinking water.

7. Also, in-text citation.

8. Secondly, improvement in the drinking water of the people

\section{Complete grammatical constructions}

Secondly, the provision of dust bins at vantage points is one of the main ways that cholera can be avoided.

Last but not least, the provision of good drinking water is the best way of preventing cholera in my locality

Also, in-text citation is one of the main ways of avoiding plagiarism".

Secondly, improvement in the drinking water of the people is a major way of preventing cholera in my locality.

All these examples in Table 8 are some of the instances where students made use of fragments in their essays. That is, instead of students to make use of full sentences in order to make their points clear and complete in meaning, they made use of these fragments which distorted the ideas that they wanted to advance in their essays. Instances of the use of fragments by these first year students of UHAS indicate their less knowledge in what constitute a complete sentence as well as the various sentence types that they can employ to construct complete and meaningful thoughts. The propositions in example 20, 21 and 23, were made in the context where the students were advancing an argument on various ways to avoid cholera in their respective districts. Therefore, the points were made to add on measures that can be put in place to avoid cholera. However, per the use of the fragment, the ideas that the students wanted to elaborate were not well captured. That is, examples 20, 21 and 23 should have been written in completed sentences as indicated in Table 8. That is, full sentences should have been used to capture the topic sentences of paragraphs in the students essays instead of the use of fragments which do not clearly bring forth the ideas the students wanted to project in their writing. The fragment in sentence 22 was made when the student was accounting for ways of avoiding plagiarism. The student therefore wanted to stress in-text citation as one way of avoiding plagiarism. However, making use of fragments instead of complete sentences did not clearly bring out the point that the student wanted to express. Like sentences 20, 21 and 23, example 22 should have also been captured in a full sentence form as captured in Table 8.

Table 9. Frequency and Rank Distribution of Errors under the Grammatical Category

\begin{tabular}{lccc}
\hline Errors & Frequency & Percentage & Rank \\
\hline Concord Errors & 302 & 52 & 1 \\
Wrong Tense Usage & 113 & 19 & 2 \\
Inappropriate Use of Articles & 97 & 17 & 3 \\
Poor Usage of Prepositions & 72 & 12 & 4 \\
TOTAL & $\mathbf{5 8 4}$ & $\mathbf{1 0 0}$ &
\end{tabular}

Table 9 provides the rank distribution of errors that were captured under the grammatical category. Under this category, four main error types were deduced from the students' essays and these were concord errors, wrong tense usage, improper use of punctuation marks and inappropriate use of prepositions.

\subsection{Errors Related to Concord}

Errors related to concord were the most dominant grammatical errors that were identified in the students' essays. That is, out of the 584 errors in the grammatical category, $302(52 \%)$ of these were related to concord errors. The analysis confirmed that concord errors were mainly linked to subject-verb disagreements. That is, on many numerous occasions, students were not able to select the required verbs to match their respective subjects, a situation that portrays the incompetence level of students with respect to the rule of usage of the English Language. Samples of subject-verb disagreements that featured in students essays are listed in Table 10. 
Table 10. Errors Related to Concord and their Corresponding Correct Forms

\begin{tabular}{|c|c|}
\hline Wrong application of concord rules & Right application of concord rules \\
\hline 9. $\quad$ This *explain* that if one is expressing... & This explains that if one is expressing... \\
\hline $\begin{array}{l}\text { 10. This short writing will }{ }^{*} \text { shows } * \text { us some } \\
\text { of the ways to avoid plagiarism. }\end{array}$ & $\begin{array}{l}\text { This short writing will show us some of the ways to avoid } \\
\text { plagiarism. }\end{array}$ \\
\hline $\begin{array}{l}\text { 11. Furthermore, complaints reaching the } \\
\text { executive body *indicates* that nurses } \\
\text { and midwives have...(sic) }\end{array}$ & $\begin{array}{l}\text { Furthermore, complaints reaching the executive body } \\
\text { indicate that nurses and midwives have...(sic) }\end{array}$ \\
\hline 12. It also *have* two ways. & It also has two ways. \\
\hline
\end{tabular}

All the sentences above indicate errors related to concord. That is, students were not able to select the correct forms of verbs to match their (verbs) corresponding subjects in their (students) sentence constructions. In example 24 for instance, the demonstrative pronoun "this" is a singular subject and as such the student should have selected a singular verb in the form of "explains" instead of "explain". This is because, the grammatical principle in concord states that a singular subject selects a singular verb whilst a plural subject selects a plural verb. With respect to example 25, the subject, in the form of "This short writing" is a singular subject and as such should have selected a singular verb but because the verb comes after the auxiliary verb "will" indicating future time, the bare form of the verb in the form of "show" should have been selected instead of "shows" whilst "complaints" a plural subject for sentence 26 should have selected a plural form of the verb in the form "indicate" instead of "indicates". On the other hand, ' $I t$ ', a singular subject in sentence 27 should have also selected a singular verb in the form of "has" but not "have". The frequency with which students made use of these errors suggests that teachers of the Communicative Skills Programme should place much emphasis on the teaching of concord so as to make students become conversant with the rules of concord.

\subsection{Errors Related to the Wrong Usage of Tense}

This type of error was the second ranked error type under the grammatical category of errors. Out of the total 584 errors that were recorded under the grammatical category, $113(19 \%)$ were linked to errors on wrong use of tense. That is, students in most situations were not able to select the right verb forms to match a particular time period that they made reference to. Typical instances identified in the data were in line with the poor usage of verbs especially after the introduction of the verb form "be". Instances of the wrong usage of tense forms in the students essays and their corresponding right forms are accounted for in Table 11.

Table 11. Wrong Usage of Verbs and their Corresponding Correct Forms

\begin{tabular}{|c|c|}
\hline Wrong forms of verbs & Right forms of verbs \\
\hline $\begin{array}{l}\text { 13. All members are *encourage* to be in the } \\
\text { ceremonial cloth. }\end{array}$ & $\begin{array}{l}\text { All members are encouraged to be in the ceremonial } \\
\text { cloth. }\end{array}$ \\
\hline 14. ...matters to be *discuss*... & ...matters to be discussed... \\
\hline $\begin{array}{l}\text { 15. It has great consequences and as such has to be } \\
\text { *avoid* }\end{array}$ & $\begin{array}{l}\text { It has great consequences and as such has to be } \\
\text { avoided. }\end{array}$ \\
\hline 16. Freedom is $*$ achieve $^{*}$ by total sacrifice & Freedom is achieved by total sacrifice. \\
\hline 17. All members are $*$ invite $*$ to the meeting & All members are invited to the meeting \\
\hline
\end{tabular}

As evident in Table 11, the verb forms "encourage", "discuss", "avoid", "achieve" and "invite" should have taken the past forms as in "encouraged", "discussed", "avoided", "achieved" and "invited".

\subsection{Errors Related to the Inappropriate Use of Articles}

This type of error in the students' essays was ranked as the second most dominant error under the grammatical category. That is, $97(12 \%)$ instances of the total 584 errors were related to the grammatical category of errors. With this error type, students were not able to distinguish between when to use the definite and indefinite articles in their grammatical constructions, a situation that impeded easy comprehension of points students discussed in their essays. Table 12, indicates instances of the inappropriate use of articles and their corresponding correct forms. 
Table 12. Wrong Usage of Articles and their Corresponding Correct Forms

\begin{tabular}{|c|c|}
\hline Wrong usage of articles & Right usage of articles \\
\hline $\begin{array}{l}\text { 18. Funeral arrangement for } * a^{*} \text { death of a } \\
\text { colleague... }\end{array}$ & Funeral arrangement for the death of a colleague... \\
\hline $\begin{array}{l}\text { 19. During our last meeting, the president of } \\
\text { association stressed on the need for members to } \\
\text { attend the programme. }\end{array}$ & $\begin{array}{l}\text { During our last meeting, the president of the } \\
\text { association stressed the need for members to attend } \\
\text { the programme. }\end{array}$ \\
\hline $\begin{array}{l}\text { 20. The association needs to select venue for the } \\
\text { upcoming elections }\end{array}$ & $\begin{array}{l}\text { The association needs to select a venue for the } \\
\text { upcoming elections. }\end{array}$ \\
\hline 21. Last but not *the* least & Last but not least \\
\hline $\begin{array}{l}\text { 22. *Plagiarism can be avoided by use of proper } \\
\text { referencing format.* }\end{array}$ & $\begin{array}{l}\text { Plagiarism can be avoided by the use of proper } \\
\text { referencing format. }\end{array}$ \\
\hline
\end{tabular}

To a very large extent, Table 12 provides a general overview of errors that relate to the wrong usage of articles. In example 33 of Table 12, the student should have introduced the definite article "the" before the word "death" but not the indefinite article " $a$ ". On the other hand, in example 34 of Table 12, the definite article "the" should have been introduced before the word "association" whilst the article "the" should have been omitted in example 36. Also, there should have been an introduction of the article "the" before the word "use" in example 37.

\subsection{Errors Related to the Poor Usage of Prepositions}

Wrong use of preposition was the fourth ranked error under the grammatical category in the 50 scripts that were analyzed. The findings revealed that $72(12 \%)$ instances of these errors out of the total 584 errors under the grammatical category were related to the wrong usage of preposition. That is, there were instances where students could not demonstrate competence in the appropriate use of prepositions. Some of these instances are highlighted in Table 13.

Table 13. Inappropriate Use of Prepositions and their Corresponding Correct Forms

\begin{tabular}{|c|c|}
\hline Wrong usage of prepositions & Right usage of prepositions \\
\hline $\begin{array}{l}\text { 23. This type of maxim stresses *on* the need to } \\
\text { back your argument with evidence. }\end{array}$ & $\begin{array}{l}\text { This type of maxim stresses the need to back your } \\
\text { argument with evidence. }\end{array}$ \\
\hline $\begin{array}{l}\text { 24. Paul Grice is a Philosopher who came *about* } \\
\text { with a theory... }\end{array}$ & $\begin{array}{l}\text { Paul Grice is a Philosopher who came out with a } \\
\text { theory... }\end{array}$ \\
\hline $\begin{array}{l}\text { 25. *A speaker can be good when he/she complies } \\
\text { this principle.* }\end{array}$ & $\begin{array}{l}\text { A speaker can be good when he/she complies with } \\
\text { this principle. }\end{array}$ \\
\hline $\begin{array}{l}\text { 26. It is one of Grice maxims which emphasizes } \\
\text { *on* the truthfulness of points to be } \\
\text { discussed. }\end{array}$ & $\begin{array}{l}\text { It is one of Grice maxims which emphasizes the } \\
\text { truthfulness of points to be discussed. }\end{array}$ \\
\hline
\end{tabular}

Table 13, provides an overview of the wrong usage of prepositions in students essays. The examples show that most of the students do not know when to make use of prepositions in their essays as evident in examples 38, 40 and 41. Aside this, students lack knowledge in selecting the right prepositions when the need arises for them to make use of them in their sentences. An example of this can be found in example 39.

\section{Conclusions}

From the findings of the study, it is clear that after going through the Academic and Communicative Skills programme for two semesters, first year students of the University of Health and Allied Sciences are not able to effectively apply the rules of usage of the English Language. This might be related to the fact that prominence is not given to the Academic and Communicative Skills Programme at UHAS. That is, out of the 50 scripts that were analyzed, 1,050 errors were detected, a situation that needs immediate attention to save the image of UHAS and also help the graduates from this university to be well equipped in the field of Academic Writing and Communicative Skills so as to enable them compete confidently both at the international and local levels. With these 1,050 errors that were detected in the students scripts, 24 (2.3\%) were related to the structural category of errors, 442 (42.1\%) were linked to errors within the mechanical category whilst $584(55.6 \%)$ of these errors were those within the grammatical categories of errors. It is also concluded that the poor state of writing by UHAS students might be 
associated with the poor attitudes of students towards the Academic and Communicative Skills Programme. The poor attitudes of students towards the Academic and Communicative Skills Programme emanate from the popular discourse on UHAS campus that students reading health related programmes do not really have to spend more credit hours in courses like Academic and Communicative Skills and as such students give less attention to it. That is, this problem is linked to the fact that Academic and Communicative Skills on UHAS campus has not been given the needed space and time as it is done at other universities in Ghana.

\section{Recommendations}

Based on the poor writing skills exhibited by first year UHAS students, I make these recommendations. First, I would recommend that the credit hours for teaching Academic and Communicative Skills should be increased from five hours to six hours and if possible, it should be extended to the second year. This therefore suggests that the idea to make Academic and Communicative Skills a non-scoring course should not be entertained. Aside this, the popular discourse on UHAS campus that students do not need to spend more credit hours in Academic and Communicative Skills because it is an "auxiliary" course should be discarded. Also, the Academic and Communicative Skills Programme should be restructured to cater for more grammar topics so as to help students write error-free texts. Coupled with these, I recommend that members of the university community should make a conscious effort to make students understand and appreciate the importance of reading Academic and Communicative Skills at the university level despite the fact that students might be reading health related programmes. Finally, it is my humble plea that if the powers that be in the university want to make any amendments to the Academic and Communicative Skills programme, they have to familiarize themselves with how the programme is organized and structured in other universities so as to avoid taking any decision that will disadvantage students of the University of Health and Allied Sciences.

\section{Acknowledgements}

I would like to extend my profound gratitude to my brother and friend, Mr. Emmanuel Asare Boakye, for encouraging me to publish this paper. In fact, it was through his motivational words that encouraged me to come out with this research work. I would also thank Mrs. Patricia Anna Mensah and Mr. Innocent Akorli Selassie for proofreading and editing this work. Many thanks also go to my father; Mr. Sarfo Amoakohene, My mother; Lydia Agyeiwaah and my siblings; Bright Amoakohene, Bernice Amoakohene and Deborah Amoakohene for their unflinching support.

\section{References}

Adjei, A.A. (2015). Analysis of subordination errors in students' writings: A study of selected teacher training colleges in Ghana. Journal of Education and Practice, 6(8), 62-77.

Afful, J. B. (2007). Academic literacy and communicative skills in the Ghanaian university: A proposal. Nebula, 4(3), 141-159.

Afful, J. B., \& Tekpetey, B. K. (2011). Oral testimonies among Christians on a university campus in Ghana. The International Journal of Language Society and Culture, 32, 1-10.

Al-Buainain, H. (n.d.). Students' writing in ESL: A case study. Retrieved on $29^{\text {th }}$ March, 2017 from file://D://error\%2oa/al-buainainhaifa-STUDE.pdf.

Amua-Sekyi, E.T. (2000). The status of English as a subject in an English medium context: The Ghanaian situation. The Oguaa Educator, 12(2).

Anyidoho, L.A. (2002). Analysis of the writing of final year university students. Ghanaian Journal of English Studies, 1, 58-72.

Awuah-Boateng, P. A. (1998). An analysis of students' errors based on a diagnostic test for first year students at the beginning of the 1996/97 academic year (An unpublished master's thesis). Department of English, University of Cape Coast, Cape Coast, Ghana.

Brown, H.D. (1994). Principles of language learning and teaching. Englewood Cliffs, N.J: Prentice-Hall.

Cedar, P. S. (2004). Transferability and translatability of idioms by Thai-speaking learners of English. Dissertation Abstracts International, 64(08), 2570. (UMI No. 3101068).

Corder, S. P. (1974). Error analysis. The Edinburgh Course in Applied Linguistics, 3, 122-131.

Dako, K., Denkabe, A. \& Forson B. (1997). The Ghanaian university students' knowledge of grammar. English in Ghana, Kropp Dakubu, M. E. (ed.), GESA, Black Mask, Accra, pp. 53-68. 
Dako, K. (1997). Features of stylistic versatility in English as observed in the writing of graduates, English in Ghana, Kropp Dakubu, M. E. (ed.), GESA, Black Mask, Accra, 263-274.

Ellis, R. (1994). The study of second language acquisition. Oxford: Oxford University Press.

Gbeze, R. K. (1997). Error analysis of communicative skills examination scripts of the university of cape coast. Unpublished undergraduate dissertation. Department of English, University of Cape Coast, Cape Coast Ghana.

Gogovi, G. A. (1997). Intensifier + verb collocation in English: A case study of post diploma usage in the University of Education, Winneba. English in Ghana, Kropp Dakubu, M. E. (ed), GESA, 46-52.

Gumperz, J. (2009). The speech community. Linguistic Anthropology: A Reader, 1, 66.

Gyasi, I. K. (1990). The State of English in Ghana. English Today, 23, 24-26. https://doi.org/10.1017/S0266078400004879

Hamdi, S. (2005). An analysis of written grammatical errors of Tunisian learners of English in EFL context. Tunisia: ISEAH Institute of Kef.

Hourani, T. (2008). An analysis of the common grammatical errors in the English writing made by 3rd secondary male students in the Eastern Coast of the UAE ( Master's thesis). British University of Dubai, Dubai, UAE.

James, C. (1998). Errors in language learning and use. London: Longman.

Khansir, A. (2013). Error analysis and second language writing. Theory and Practice in Language Studies, 3(2), 363. https://doi.org/10.4304/tpls.3.2.363-370

Lado, R. (1957). Linguistics across cultures. Ann Arbor: University of Michigan Press.

Listiani, M. (2014). An error analysis of students writing: A descriptive study of students' English writing of second grade of SMK Bakti purwokento (An unpublished post diploma degree thesis). Muhammadiyah University of Purwokerto, Central Java, Republic of Indonesia.

Mahama, E. (2012). Ghanaian English and its implications for academic writing. A Case Study of English on the Navrongo Campus of University for Development Studies Ghana. Research on Humanities and Social Sciences, 2(11), $56-63$.

Mireku-Gyimah, P. (2014). Analysis of errors in the English of final year university students: A case study at the University of Mines and Technology. Journal of ELT and Applied Linguistics (JELTAL), 2(4), 23-46.

Norrish, J. (1983). Language learners and their errors. London: The Macmillan Press.

Odamtten, H., Denkabe, A. \& Tsikata, I. (1994). The problem of English language skills at the university level: A case study of first year Law and Administration Students. Legon Journal of the Humanities, 7, 95-125.

Pineteh, E. (2013). The academic writing challenges of undergraduate students: A South African case study. International Journal of Higher Education, 3(1), 12. https://doi.org/10.5430/ijhe.v3n1p12

Quibol-Catabay, M.(2016). Error analysis in students' writing. International Journal of Advanced Research Management and Social Sciences, 5(1), 131-148.

Richards, J. \& Renandya, W. (Eds.) (2002). Methodology in language teaching: An anthology of current practice. Cambridge: Cambridge University Press. https://doi.org/10.1017/CBO9780511667190

Sarfraz, S. (2011). Error analysis of the written English essays of Pakistani undergraduate students: A case study. Asian Transactions on Basic \& Applied sciences, 1(3), 29-5.

Tarigan, D. (1995). Pengajaran Analisis Kesalahan Berbahasa. Bandung :Angkasa.

Ulla, M. B. (2014). Analysis of the language errors in writing among BSEE and AB English students. European Journal of Academic Essays, 1(3), 39-47. 